\title{
BMJ
}

\section{Functional decline after incident wrist fractures-Study of Osteoporotic Fractures: prospective cohort study}

\author{
Beatrice J Edwards, associate professor of medicine and orthopaedics, ${ }^{1}$ ling Song, biostatistics manager, ${ }^{2}$ \\ Dorothy D Dunlop, associate professor, ${ }^{2}$ Howard A Fink, clinician investigator/staff physician, ${ }^{3}$ Jane A Cauley, \\ professor and vice chair for research ${ }^{4}$
}

${ }^{1}$ Bone Health and Osteoporosis Center, Division of Geriatrics,

Feinberg School of Medicine, Northwestern University, 645 N Michigan, Chicago, IL 60611, USA

${ }^{2}$ Institute for Health Care Studies, Department of Medicine, Division

of Rheumatology, Feinberg School of Medicine, Northwestern

University

${ }^{3}$ Geriatric Research Education and Clinical Center, Center for Chronic Disease Outcomes Research, VA Medical Center, Minneapolis, MN, USA

${ }^{4}$ Department of Epidemiology, Graduate School of Public Health, University of Pittsburgh,

Pittsburgh, PA, USA

Correspondence to: $\mathrm{B}$ Edwards Bje168@northwestern.edu

Cite this as: BMJ 2010;341:C3324 doi:10.1136/bmj.c3324

\section{ABSTRACT}

Objective To study the effect of an incident wrist fracture on functional status in women enrolled in the Study of Osteoporotic Fractures.

Design Prospective cohort study.

Setting Baltimore, Minneapolis, Portland, and the Monongahela valley in Pennsylvania, USA

Participants 6107 women aged 65 years and older without previous wrist or hip fracture recruited from the community between September 1986 and October 1988. Main outcome measure Clinically important functional decline, defined as a functional deterioration of 5 points in five activities of daily living each scored from 0 to 3 (equivalent to one standard deviation decrease in functional ability).

Results Over a mean follow-up of 7.6 years, 268 women had an incident wrist fracture and 41 (15\%) of these developed clinically important functional decline. Compared with women without wrist fractures, those with incident wrist fractures had greater annual functional decline after adjustment for age, body mass index, and health status. Occurrence of a wrist fracture increased the odds of having a clinically important functional decline by $48 \%$ (odds ratio $1.48,95 \%$ confidence interval 1.04 to 2.12), even after adjustment for age, body mass index, health status, baseline functional status, lifestyle factors, comorbidities, and neuromuscular function.

Conclusions Wrist fractures contribute to clinically important functional decline in older women.

\section{INTRODUCTION}

Wrist fractures are the most common upper extremity fractures in older adults. The annual incidence is 8-10 per 1000 person years, ${ }^{12}$ compared with an incidence of hip fractures of 7 per 1000 person years. ${ }^{3}$ Wrist fractures are more common in women under the age of 75 years, whereas hip fractures become more common in women aged over 75. Wrist fractures most commonly result from a fall sustained while walking and occur when the person is still healthy, active, and functionally independent. ${ }^{4}$ Risk factors for wrist fractures include low bone mineral density, no previous oestrogen use, a history of two or more falls in the preceding year, and a previous fracture after the age of 50. Poor cognitive status increases the risk for wrist fracture in women over the age of 75 years. ${ }^{5}$

Although the functional impairment attributed to vertebral fractures and hip fractures has been well documented, the consequences of wrist fractures on functional decline have been less well studied. Some investigators have postulated that up to half of women who sustain a wrist fracture may have continuing residual impairment and pain after the fracture has been treated. ${ }^{67}$ Wrist fractures may be as disabling as vertebral or hip fractures with respect to some specific activities of daily living such as meal preparation. Some women who have wrist fractures may lose their functional independence; however, previous studies have been limited by small sample size..$^{8-12}$

To quantify better the clinical impact of wrist fractures, we used the Study of Osteoporotic Fractures cohort of older women to examine the contribution of incident wrist fractures to subsequent functional decline over time and to describe additional risk factors for these functional changes.

\section{METHODS}

\section{Participants}

The Study of Osteoporotic Fractures is an ongoing US multicentre prospective cohort study that evaluated risk factors for hip fracture in 9704 primarily white women aged 65 years and older. ${ }^{13}$ Women were recruited mainly from population based listings between September 1986 and October 1988. Study clinics were established in Baltimore, Maryland; Minneapolis, Minnesota; the Monongahela valley near Pittsburgh, Pennsylvania; and Portland, Oregon. Women participated in standardised interviews and clinical examinations approximately every two years; these covered sociodemographic aspects and health, lifestyle, and other risk factors for fractures.

From the original 9704 women enrolled, we excluded from the analyses 1245 women who reported previous wrist fracture $(\mathrm{n}=1097)$ or hip fracture $(n=184)$ at baseline (36 reported both wrist and hip fracture) and 33 non-white women. For analysis purposes, we restricted our analysis to 7490 women who reported less severe functional impairment (functional 
difficulty score 0-10) at baseline and had complete baseline information. We excluded women with severe functional impairment at baseline (score $\geq 11$ / 15) because of the ceiling effect of the measure, as these women would not be able to decline by more than 5 points. From among these participants, we further excluded 1383 women who had incomplete follow-up data for functional measures, resulting in a final analysis cohort of 6107 women (figure). All participants signed an informed consent form.

\section{Functional outcome measures}

The Study of Osteoporotic Fractures used the 1984 national health interview survey supplement on aging to assess functional difficulty ${ }^{14}$; these measures have been validated in several studies. ${ }^{15-19}$ These five functional measures or activities of daily living comprised meal preparation, heavy housekeeping, ability to climb 10 stairs, shopping, and getting out of a car. Each activity was self reported on a 0-3 Likert-type scale $(0=$ no difficulty in performing the activity, $1=$ some difficulty, $2=$ much difficulty, $3=$ unable to perform the activity). The total functional difficulty score across the five activities was $0-15$. We defined clinically important functional decline, originally described by Lin et al, ${ }^{20}$ as a deterioration in functional score of 5 points or more or the equivalent change of one standard deviation. ${ }^{17}$ The outcome analysed was presence/ absence of a clinically important functional decline between the visit most recently preceding the wrist fracture and the visit most immediately following the wrist fracture. We analysed the control group in a similar manner to the wrist fracture group across all visits.

\section{Incident fractures}

Self reports of fractures (wrist, vertebral, and hip) were solicited by a postcard or phone call every four months. We defined wrist fractures as fractures of the distal radius or ulna (Colles' fracture), or both. Self reported fractures were confirmed by a copy of the radiographic report and were centrally adjudicated. We included fractures that occurred up to the sixth visit (1997-8). Follow-up was 99\% complete.

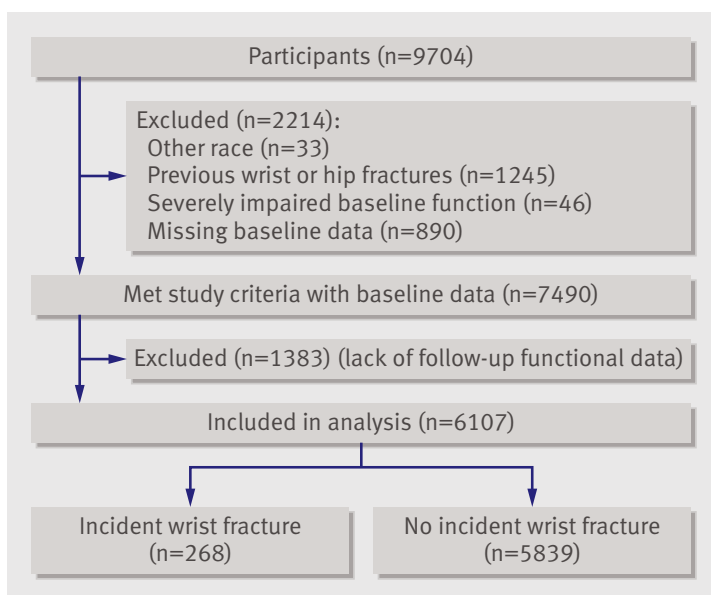

Selection of participants

\section{Other risk factors}

Demographic/anthropometric characteristics -Age, body mass index, and education were recorded. Except for education, these variables were evaluated at each study visit, approximately every 24 months.

Skeletal measures - A standardised protocol was used to measure bone mineral density of the wrist (Osteo Analyzer, Siemens-Osteon, Wahiawa, HI) during the baseline clinic visit. ${ }^{21}$ Bone mineral density of the proximal femur and spine was measured in the antero-posterior projection at the two year follow-up visit with a Hologic QDR 1000 scanner (Hologic, Waltham, MA). Scans were reviewed at the University of California San Francisco.

Lifestyle covariates - Smoking status, alcohol use, and current physical activity were evaluated at each study visit.

Social networks_During the second visit (1988-90), participants completed the Lubben social network scale. This scale is a validated 10 item self report inventory assessing family (three items), friends (three items), and interdependent relationships (four items). Responses are summed for a composite value. ${ }^{2223}$

Comorbidities - We assessed comorbidities by self report of a physician's diagnosis of Parkinson's disease, arthritis, diabetes, stroke, and chronic obstructive pulmonary disease. A modified version of the minimental status examination with a range from 0 to 26 was administered; cognitive impairment was defined as the change in score from baseline to follow-up that exceeded the observed average change in score by at least one standard deviation or by 3 points. ${ }^{24} \mathrm{We}$ defined weight loss as $10 \%$ or greater loss compared with baseline weight. Incident falls were collected from postcard responses. Falls were recorded from postcard surveys as well as on yearly visits. Self reported health was categorised as excellent, good, fair, poor, or very poor. ${ }^{18}{ }^{1925-27}$ Drug use for this analysis was limited to oestrogen use.

Neuromuscular measures - A composite of measures of muscle strength, neuromuscular coordination, reaction time, and visual measures has been shown to predict risk of fall in many studies. ${ }^{28-30}$ Gait speed was measured as the mean of two walking trials at the participant's usual pace over a $6 \mathrm{~m}$ course (reliability, $\mathrm{r}=$ 0.84). ${ }^{2031}$ Grip strength was measured as the best of two trials on the dominant side with a Preston grip dynamometer (Takei Kikikogyo, Tokyo, Japan). ${ }^{15}$ Maximal knee extension was measured with the participant sitting with her knee flexed at $80^{\circ}$. A strap connected to a strain gauge was placed around the participant's dominant leg above the ankle malleoli. Each participant was instructed to straighten her leg slowly and as forcefully as possible. The best score of three trials was recorded. ${ }^{32}$ Hip abductor strength was measured with participants in the supine position with the leg fully extended and supported (reliability, $r=0.8$ ). For triceps extension strength, participants were tested in the supine position, with the elbow flexed to $90^{\circ}$ (reliability, $\mathrm{r}=0.93$ ). Chair stand performance was assessed as the time needed to stand up from a chair without using 
the arms five times. In the tandem stand, women were asked to stand with one foot in front and the other behind, touching heel to toe (as if standing on a line or balance beam) with their eyes open for 10 seconds; if they were able to hold the position, they were asked to perform the same tandem stand with their eyes closed. If they were able to hold the position for more than 10 seconds, it was recorded as positive response (yes/no). The foot tap test measured the number of seconds taken to complete 10 taps of the ball of the foot on alternating $7.5 \mathrm{~cm}$ diameter circles placed 30 $\mathrm{cm}$ from centre to centre (reliability, $\mathrm{r}=0.87$ ); the dominant side was tested on the basis of reported right or left handedness. In the "uses arms to complete step-ups test," participants were asked to step up or down one step, with or without use of a handrail. The ability and time to complete five step-ups successfully was recorded. ${ }^{33}$

Vision-Depth perception was assessed using the Howard-Dolman apparatus, with distance correction used, and scored as the standard deviation of four trials. Visual acuity and contrast sensitivity were measured (separately averaging the scores for low and high spatial frequencies). ${ }^{2834-36}$

\section{Statistical analysis}

Comparisons of baseline characteristics between women with and without wrist fracture used $\chi^{2}$ tests for categorical characteristics and $t$ tests for continuous characteristics. For continuous characteristics that had skewed distributions, we used the Wilcoxon rank sum test. We used SAS v9 software for analyses. We defined the incident wrist fracture study group as women with a new (incident) fracture after visit 1 , and we considered the women without incident fracture as the control group. Women with incident wrist fracture contributed to the non-fracture group before their fracture.

For women who had an incident wrist fracture, their visits before the fracture contributed to the control group visits and their visits after the fracture contributed to the case group visits. For women without an incident risk fracture, all visits contributed to control group visits. For all women, the outcome was a clinically meaningful increase ( $\geq 5$ units) in functional difficulty score between two consecutive visits (baseline to visit 1 at year 2 , visit 1 at year 2 to visit 2 at year 4 , and so on). We used longitudinal data analysis with logistic regression with generalised estimating equations to validly handle these time dependent outcomes and the associated time dependent case-control status. The rationale was that this approach accounted for the complete longitudinal experience of this cohort.

To validly account for potential correlated observations over time from the same person, we evaluated the association of wrist fractures with clinically important functional decline by using multiple logistic regression analysis with generalised estimating equations, controlling for other potential risk factors. ${ }^{378} \mathrm{We}$ entered wrist fracture status and other potential risk factors as time dependent covariates, permitting wrist fracture values to be updated to account for changing status over time. The form of the analysis is $\operatorname{logit}\left(\mathrm{Y}_{\mathrm{v}+1}\right)=\mathrm{a} 0$ $+\mathrm{a} 1 \times \mathrm{WristFx} \mathrm{x}_{\mathrm{v}}+\mathrm{b} 1 \times \mathrm{X} 1_{\mathrm{v}}+\ldots \mathrm{bp} \times \mathrm{Xp} \mathrm{p}_{\mathrm{v}}$, where the covariates are $\mathrm{WristFx}_{\mathrm{v}}$ tracking the occurrence of a wrist fracture by the current visit $\mathrm{v}$ and other risk factors $\mathrm{X} 1_{\mathrm{v}}, \ldots ., \mathrm{Xp}$, at visit $\mathrm{v}$, and the outcome $\mathrm{Y}_{\mathrm{v}+1}$ tracks the presence/absence of a clinically important functional decline at the subsequent visit $\mathrm{v}+1$.

Results are reported as odds ratios; an associated 95\% confidence interval that excludes one indicates a significant association of a risk factor with the outcome. Before doing multiple regression analysis, we screened for problematic multi-colinearity as described by Greene. $^{39}$

\section{RESULTS}

Among 6107 women included in the analyses, the mean follow-up was 7.6 (range 1.3-12.0) years. As shown in the figure, $268(4.4 \%)$ women had an incident wrist fracture; their mean duration of functional followup after the wrist fracture was 6.3 (range 1.0-9.5) years. The mean interval from occurrence of wrist fracture to biannual examination was 1.1 years (SD 3 months; range 6-19 months).

Table 1 shows that women who had an incident wrist fracture had significantly lower bone mineral density in the distal radius at baseline (0.33 v $0.37 \mathrm{~g} /$ $\left.\mathrm{cm}^{2}, \mathrm{P}<0.001\right)$, were more likely to report falls (34.3 $v$ $27.6 \%, \mathrm{P}<0.001)$ in the year before the incident wrist fracture, and were less likely to be current or past oestrogen users $(33.1 \% v 44.3, \mathrm{P}<0.001)$, compared with their counterparts who did not have wrist fractures. In addition, they had significantly better functional status at baseline $(0.51 v 0.76, \mathrm{P}=0.004)$, a higher gait speed (1.04 $v 1.09 \mathrm{~m} / \mathrm{s}, \mathrm{P}<0.001)$, and greater hip abduction strength (11.81 v $11.23 \mathrm{~kg}, \mathrm{P}=0.004)$ and were able to stand up from a chair more quickly $(5.498 v 5.776 \mathrm{~s}$, $\mathrm{P}=0.006)$ (table 1).

We evaluated the relation of a wrist fracture to a clinically important functional decline (5 point decline or equivalent to $1 \mathrm{SD}$ ) over the following years. Among the 268 women who had initial wrist fracture, 41 (15\%) had clinically significant functional decline, compared with $714(12.2 \%)$ controls $(\mathrm{P}=0.02)$. In unadjusted analyses, wrist fractures significantly increased the risk of clinically important functional decline by $51 \%$ (odds ratio $1.51,95 \%$ confidence interval 1.06 to 2.14 ) (table 2). Wrist fracture remained an important predictor of functional decline after adjustment for age, body mass index, health status, comorbidities, and neuromuscular function (odds ratio 1.48, 1.04 to 2.12). Social support was measured at year 2 in a subset of 5189 of the participants. In a sensitivity analysis that incorporated this information, social support was not a predictor of functional decline and the effect of the other covariates remained the same. Because social support did not influence our results, and including it would reduce our sample size, we did not incorporate it in the final model.

Results from the final multiple logistic regression model show the relative strength of wrist fracture compared with other risk factors (table 3). Other predictors 
Table 1|Baseline characteristics of women with and without wrist fractures. Values are numbers (percentages) unless stated otherwise

\begin{tabular}{|c|c|c|c|}
\hline & \multicolumn{2}{|c|}{ Wrist fractures } & \multirow[b]{2}{*}{ P value } \\
\hline & Yes $(n=268)$ & No $(n=5839)$ & \\
\hline \multicolumn{4}{|l|}{ Demographic characteristics } \\
\hline Mean (SD) age (years) & $71.15(4.58)$ & $71.06(4.89)$ & $0.772^{\star}$ \\
\hline Education $<12$ years & $51(19)$ & $1206(20.7)$ & 0.520 \\
\hline Mean (SD) body mass index & $26.02(4.02)$ & $26.44(4.37)$ & $0.122^{*}$ \\
\hline Mean (SD) functional status & $0.51(1.19)$ & $0.76(1.58)$ & $0.004 \dagger$ \\
\hline \multicolumn{4}{|l|}{ Skeletal measures } \\
\hline Mean (SD) distal radius bone mineral density $\left(\mathrm{g} / \mathrm{cm}^{2}\right)$ & $0.33(0.07)$ & $0.37(0.08)$ & $<0.001^{\star}$ \\
\hline \multicolumn{4}{|l|}{ Lifestyle factors } \\
\hline $\begin{array}{l}\text { Moderate or high intensity recreational physical } \\
\text { activity at least monthly }\end{array}$ & $114(43)$ & $2234(38.3)$ & 0.159 \\
\hline Mean (SD) alcohol drinks in previous 30 days & $1.70(3.26)$ & $1.82(3.71)$ & $0.636 \dagger$ \\
\hline Current smoking & $21(8)$ & $528(9.0)$ & 0.499 \\
\hline \multicolumn{4}{|l|}{ Health factors } \\
\hline \multicolumn{4}{|l|}{ Comorbidity: } \\
\hline Diabetes mellitus & $11(4)$ & $383(6.6)$ & 0.110 \\
\hline Weight loss & $10(4)$ & $297(5.1)$ & 0.321 \\
\hline Chronic obstructive pulmonary disease & $22(8)$ & $486(8.3)$ & 0.947 \\
\hline Cerebrovascular accident & $8(3)$ & $155(2.7)$ & 0.743 \\
\hline Parkinson's disease & $0(0)$ & $28(0.5)$ & 0.256 \\
\hline Arthritis & $159(59)$ & $3625(62.1)$ & 0.364 \\
\hline Poor cognition & $25(9)$ & $484(8.3)$ & 0.547 \\
\hline \multicolumn{4}{|l|}{ Falls in previous year: } \\
\hline None & $176(66)$ & $4224(72.3)$ & \multirow{3}{*}{$<0.001$} \\
\hline One & $45(17)$ & $1070(18.3)$ & \\
\hline Two or more & $47(18)$ & $545(9.3)$ & \\
\hline \multicolumn{4}{|l|}{ Overall health: } \\
\hline Excellent & $119(44)$ & $1929(33.0)$ & \multirow{5}{*}{0.001} \\
\hline Good & $126(47)$ & $3061(52.4)$ & \\
\hline Fair & $22(8)$ & $789(13.5)$ & \\
\hline Poor & $1(0.4)$ & $56(1.0)$ & \\
\hline Very poor & $0(0)$ & $4(0.1)$ & \\
\hline \multicolumn{4}{|l|}{ Oestrogen use: } \\
\hline Never & $179(67)$ & $3253(55.7)$ & \multirow{3}{*}{$<0.001$} \\
\hline Past & $70(26)$ & $1685(28.9)$ & \\
\hline Current & $19(7)$ & $901(15.4)$ & \\
\hline \multicolumn{4}{|l|}{ Neuromuscular measures } \\
\hline Abnormal depth perception & $38(14)$ & $881(15.1)$ & 0.684 \\
\hline Visual acuity $<20 / 40$ & $210(79)$ & $4786(82.0)$ & 0.134 \\
\hline Mean (SD) contrast sensitivity, low spatial frequency & $75.42(34.79)$ & $75.86(35.37)$ & $0.845^{\star}$ \\
\hline Mean (SD) gait speed/stride length $(\mathrm{m} / \mathrm{s})$ & $1.04(0.21)$ & $1.09(0.21)$ & $<0.001^{*}$ \\
\hline Mean (SD) grip strength & $21.56(3.89)$ & $21.29(4.20)$ & $0.296^{*}$ \\
\hline Mean (SD) maximum right knee extension (kg) & $18.68(4.74)$ & $18.19(5.06)$ & $0.126^{*}$ \\
\hline Mean (SD) hip abduction (kg) & $11.81(3.05)$ & $11.23(3.27)$ & $0.004^{\star}$ \\
\hline Mean (SD) maximum triceps extension $(\mathrm{kg})$ & $10.78(2.42)$ & $10.77(2.69)$ & $0.917^{*}$ \\
\hline Mean (SD) chair stand (s) & $5.498(1)$ & $5.776(1)$ & $0.006^{*}$ \\
\hline Mean (SD) foot tapping (s) & $4.68(1.36)$ & $4.91(1.74)$ & $0.079 \dagger$ \\
\hline Uses arms to step up/step down & $12(5)$ & $409(7.0)$ & 0.110 \\
\hline
\end{tabular}

*Non-parametric Wilcoxon rank sum test comparing medians of people with and without incident wrist fracture. †Student's $t$ test comparing means of people with and without incident wrist fracture.

contributing to a clinically important functional decline included having had an incident hip fracture (odds ratio $4.86,3.32$ to 7.12 ), followed by poor and fair health (poor health 2.69, 1.56 to 4.63; fair health $2.40,1.88$ to 3.06$)$, Parkinson's disease $(2.19,1.05$ to
4.56), weight loss (2.12 per SD, 1.05 to 2.56 ), and stroke $(1.65,1.24$ to 2.20$)$. The magnitude of functional decline attributed to incident wrist fracture was similar to that seen for falls (odds ratio 1.58, 1.28 to 1.95), arthritis $(1.48,1.23$ to 1.79$)$, and diabetes mellitus $(1.36,1.04$ to 1.78$)$ (table 3$)$.

\section{DISCUSSION}

In this cohort of older women followed up for an average of 7.6 years, we found that those with incident wrist fractures were approximately 50\% more likely than those without fractures to have a clinically important functional decline, as defined by worsening ability to prepare meals, perform heavy housekeeping, climb 10 stairs, go shopping, and get out of a car. Wrist fractures contributed to clinically important functional decline even after adjustment for demographics, health status, baseline functional status, lifestyle factors, comorbidities, and neuromuscular function. The effect of a wrist fracture on clinically important functional decline was as significant as that of other established risk factors for functional decline such as falls, diabetes, and arthritis. Our findings highlight the personal, public health, and policy implications of wrist fractures.

\section{Comparison with other studies}

Our results support previous work, albeit smaller studies, showing that wrist fractures cause substantial functional impairment across a spectrum of quality of life domains, particularly when the dominant hand is affected. ${ }^{40}$ Specific tasks that are affected by wrist fracture have included opening and closing jars, carrying heavy objects, opening doors, cutting food, pouring liquid from a pitcher, lifting pots and pans, turning a key, rising from chair, washing floor and walls, and opening and closing taps. ${ }^{40}$ Moreover, displaced or intra-articular wrist fractures seem to more often be associated with poor functional outcomes. ${ }^{4142}$ Our findings contrast with previous work suggesting that wrist fractures fail to affect functional ability or quality of life in older women. ${ }^{43}$

Some controversy exists about the relation between wrist fractures and mortality. Some studies have shown that wrist fractures result in functional impairment and increased mortality. ${ }^{4-46}$ However, these studies have been limited by small sample size. Browner and collaborators did not identify an effect of wrist fractures on mortality within the Study of Osteoporotic Fractures cohort. $^{47}$

The personal implications of a wrist fracture on functional decline are apparent. Wrist fractures in older women may contribute to long term functional impairment. A wrist fracture will often result from a fall sustained while walking when the person is still able to mount a protective response such as stretching out an arm. ${ }^{4849}$ Consequently, wrist fractures occur when the woman is still physically active and functionally independent. Our findings suggest that a wrist fracture starts a progressive functional decline that is still evident at three years. This would seem to contrast with younger women in whom functional recovery after a 
Table 2|Relation of wrist fracture to clinically important functional decline

Odds ratio of clinically significant functional decline

Adjustment factors related to incident wrist fracture $(95 \% \mathrm{Cl}) *$

Unadjusted

1.51 (1.05 to 2.14$)$

Adjusted for age, body mass index, health status

66 (1.17 to 2.36$)$

Adjusted for age, body mass index, health status,

1.48 (1.04 to 2.12$)$

comorbidities $†$, and neuromuscular function $\ddagger$

*Multiple logistic regression analysis showing odds ratio for functional decline in next year for people with incident wrist fracture compared with those without wrist fracture.

†Chronic obstructive pulmonary disease, arthritis, diabetes mellitus, stroke, Parkinson's disease.

fDepth perception, visual acuity, visual contrast sensitivity, grip strength, maximum knee extension, hip

abduction, maximum triceps extension, chair stand, foot tapping, uses arms to stand up.

wrist fracture is almost complete by six months. ${ }^{5051} \mathrm{We}$ hypothesise that older women may have slower recovery than do younger women after wrist fractures or may develop permanent disability, although further research is needed in this area. We propose that deficits in tasks that require upper extremity function, such as shopping, meal preparation, and heavy housekeeping, would be expected. In addition, older women with wrist fractures may have more difficulty climbing steps or getting out of a car owing to their reliance on handrails or their need to push off from the seat to get out of a car. ${ }^{50}$ Many factors related to incident decline are modifiable and suggest that interventions could prevent functional decline.

\section{Policy implications}

These findings have important public health and policy implications. ${ }^{52}$ One way to prevent the effects of

Table $3 \mid$ Multiple logistic regression of risk factors for clinically important functional decline

\begin{tabular}{|c|c|}
\hline Characteristic & Odds ratio* $(95 \% \mathrm{Cl})$ \\
\hline Age (per year) & 1.06 (1.05 to 1.08$)$ \\
\hline Baseline functional status score (per unit) & 0.91 (0.87 to 0.95$)$ \\
\hline Wrist fracture (post-baseline) & 1.48 (1.04 to 2.12$)$ \\
\hline Hip fracture & $4.86(3.32$ to 7.12$)$ \\
\hline \multicolumn{2}{|l|}{ Comorbidity: } \\
\hline Diabetes mellitus & 1.36 (1.04 to 1.78$)$ \\
\hline Weight loss & $2.12(1.05$ to 2.56$)$ \\
\hline Stroke & 1.65 (1.24 to 2.20$)$ \\
\hline Parkinson's disease & $2.19(1.05$ to 4.56$)$ \\
\hline Arthritis & 1.48 (1.23 to 1.79$)$ \\
\hline \multicolumn{2}{|l|}{ Falls in previous year: } \\
\hline None & Reference \\
\hline Two or more & 1.58 (1.28 to 1.95$)$ \\
\hline \multicolumn{2}{|l|}{ Overall health: } \\
\hline Excellent & Reference \\
\hline Good & $1.26(1.03$ to 1.54$)$ \\
\hline Fair & 2.40 (1.88 to 3.06$)$ \\
\hline Poor/very poor & 2.69 (1.56 to 4.63$)$ \\
\hline \multicolumn{2}{|l|}{ Neuromuscular measures: } \\
\hline Grip strength (per unit) & 1.58 (1.28 to 1.95$)$ \\
\hline Hip abduction (per unit) & 2.40 (1.88 to 3.06$)$ \\
\hline Maximum triceps extension (per unit) & 2.69 (1.56 to 4.63$)$ \\
\hline Uses arms to step up/step down & 1.23 (1.02 to 1.48$)$ \\
\hline
\end{tabular}

osteoporosis is through early diagnosis and treatment to reduce the number of hip and vertebral fractures, thereby preserving a person's mobility, functionality, and independence. ${ }^{53}$ Our findings highlight the need to emphasise wrist fractures as being associated with considerable impairment in functionality and independence. Of particular relevance is the fact that these fractures are widespread and occur in relatively fit older women. The 326838 wrist fractures reported annually account for $19 \%$ of total fractures in the United States. ${ }^{54}$ Approximately $11.6 \%$ of all women in the United States will have a wrist fracture. ${ }^{55}$ This study suggests that measures to prevent wrist fractures may reduce functional decline in older women. Primary prevention would include diagnosis and treatment of low bone mass and osteoporosis, as well as preventing falls in older adults through the use of physical therapy, exercise, vitamin D, and home safety evaluations. For secondary prevention, prompt rehabilitation after a wrist fracture - such as occupational therapy to include upper extremity rehabilitation and physical therapy for gait and balance training - may result in improved clinical outcomes.

\section{Strengths and limitations of study}

Several aspects of our methods deserve comment. We studied community dwelling, largely healthy, physically active, white women. Study findings may not apply to men, to women living in institutions or in poor health, or to other ethnic groups. Health status was self reported, and we lacked information on the severity of comorbid conditions. We were therefore limited in our ability to assess the impact of comorbidities on the fracture related disability. Additionally, functional outcomes were measured every two years, which limited the capacity of these analyses to evaluate short term disability after wrist fractures or to evaluate the trajectory of recovery or decline after a wrist fracture.

We used generalised estimating equations to estimate this logistic regression using longitudinal followup data for two reasons. Firstly, this method provides valid estimates of odds ratios, which account for the potentially correlated outcomes due to repeated observations on the same person. Secondly, in the setting of non-linear models (that is, logistic regression), it provides population averaged odds ratios that permit population based inferences. This is preferred over analytical methods such as a mixed models approach that provides conditional odds ratios and does not directly permit population based inferences.

Regarding the control group, we assigned all visits over the follow-up time from women without an incident wrist fracture as control group visits; for those who developed incident risk fractures, we assigned visits before the fracture as control group visits and visits after the fracture as case group visits. This assignment was validly handled through the use of a time dependent case-control status variable.

Finally, we do not believe that regression to the mean is a concern in this analysis for two reasons. 


\section{WHAT IS ALREADY KNOWN ON THIS TOPIC}

\section{Wrist fractures are the most common upper extremity fractures in older adults}

Specific tasks affected by wrist fracture include opening and closing jars, carrying heavy objects, cutting food, lifting pots and pans, turning keys, rising from a chair, and opening and closing taps

Menopausal women often show full functional recovery after a wrist fracture

\section{WHAT THIS STUDY ADDS}

A wrist fracture in older community dwelling women was associated with a $48 \%$ increased risk for development of clinically important functional decline

The magnitude of functional decline attributed to wrist fracture was similar to that seen for falls, arthritis, and diabetes mellitus

Wrist fractures may play a role in the development of disability in older people

Firstly, we modelled the logit rather than the mean because our outcome was binary, not continuous. Specifically, our outcome was whether or not a biannual change in the function score exceeded five units. Secondly, our analysis incorporated biannual changes in functional status over six years. If regression to the mean was operating, a large functional change at one visit would be mitigated by a small change at a succeeding visit, all of which would have been included in our analysis. For this reason, we do not believe that these results are biased by a regression to the mean effect.

Despite these limitations, the study has notable strengths that include its large, geographically diverse population, rigorous adjudication of incident fractures, and 99\% complete follow-up.

\section{Conclusions}

Wrist fractures contribute to clinically important functional decline in older women. The effect of a wrist fracture on clinically important functional decline was as significant as that of other established risk factors for functional decline such as falls, diabetes, and arthritis.

Wrist fractures are common and result in clinically important functional decline in women who are fairly healthy and physically fit. Because of the magnitude of the problem and the consequences of the complications, greater public health awareness of the impact of osteoporotic wrist fractures is needed. Osteoporosis outreach should highlight the prevention of wrist fractures.

This work was presented at the annual meeting of the American Society of Bone and Mineral Research Honolulu, HI, 2007.

Contributors: BJE was responsible for the conception and general oversight of the study and was involved in analysis of data and drafting and revising the manuscript. DDD designed the analytical method, oversaw the analysis, and was involved in revision and approval of the final manuscript. JS was involved in analysis of original data and in drafting and revision of the final manuscript. HF participated in the analysis and critical review of the manuscript. JAC was involved in the analysis and in drafting and revising the manuscript. BJE is the guarantor. Funding: Funding was provided by the National Institutes of Health NIAMS and NIA under the grant numbers AG05407, AR35582, AG05394 AR35584, AR35584, AR35583,R01 AG005407, 2R01 AG005394-22A1, and 2R01 AG027574-22A1.

Competing interests: All authors have completed the Unified Competing Interest form at www.icmje.org/coi_disclosure.pdf (available on request from the corresponding author) and declare (1) no support from any company for the submitted work; (2) no relationships with any companies that might have an interest in the submitted work in the previous 3 years; (3) their spouses, partners, or children have no financial relationships that may be relevant to the submitted work; and (4) no nonfinancial interests that may be relevant to the submitted work. Ethical approval: The Office of Protection of Research Subjects approved the study, and all participants gave written informed consent. Data sharing: No additional data available.

1 Melton LJ 3rd, Chrischilles EA, Cooper C, Lane AW, Riggs BL. How many women have osteoporosis? J Bone Miner Res 1992;7:1005-10.

2 Cummings SR, Black DM, Rubin SM. Lifetime risk of hip, Colles', or vertebral fracture and coronary heart disease among white postmenopausal women. Arch Intern Med 1989;145:2445-8.

3 Melton LJ 3rd, Therneau TM, Larson DR. Long term trends in hip fracture prevalence: the influence of hip fracture incidence and survival. Osteoporos Int 1998;8:68-74.

4 Kelsey JL, Browner WS, Seeley DG, Nevitt MC, Cummings SR. Risk factors for fractures of the distal forearm and proximal humerus. $A m$ J Epidemiol 1992;135:477-89.

5 Vogt MT, Cauley JA, Tomaino MM, Stone K, Williams JR, Herndon JH. Distal radius fractures in older women: a 10 year follow up study of descriptive characteristics and risk factors: the Study of Osteoporotic Fractures. J Am Geriatr Soc 2002;50:97-103.

6 Sewart HD, Innes AR, Burke FD. Factors affecting the outcome of Colles' fracture: an anatomical and functional study. Injury 1985;16:289-95.

7 Trumble TE, Schmitt SR, Vedder NB. Factors affecting the functional outcome of displaced intra-articular distal radius fractures. J Hand Surg (Am) 1994;19:325-40.

8 McQueen M, Caspwers J. Colles' fracture-does the anatomical result affect the final function? / Bone loint Surg Br 1988;70B:649-51.

9 Greendale GA, Barrett-Connor E, Ingles S, Haile R. Late physical and functional effects of osteoporotic fracture in women: the Rancho Bernardo Study. J Am Geriatr Soc 1995;43:955-61.

10 Bacorn RW, Kurtzke JF. Colles' fractures: a study of the two thousand cases from the New York State Workmen's Compensation Board. J Bone Joint Surg (Am) 1953;35A:643-58.

11 Hughes S, Gibbs J, Dunlop D, Edelman P, Singer R, Chang RW. Predictors of decline in manual performance in older adults. J Am Geriatr Soc 1997;45:905-10.

12 Madhok R, Green S. Longer term functional outcome and societal implications of upper limb fractures in the elderly. $/ R$ Soc Health 1993:179-90.

13 Cummings SR, Nevitt MC, Browner WS, Stone K, Fox KM, Ensrud KE, et al. Risk factors for hip fracture in white women. $N$ Engl J Med 1995;332:767-73.

14 Fitti JE, Kovar MG. The supplement on aging to the 1984 National Health Interview Survey. Vital Health Stat 1987;21:1-115.

15 Nelson HD, Nevitt MC, Scott JC, Stone KL, Cummings SR. Smoking, alcohol, and neuromuscular and physical function of older women. JAMA 1994;272:1825-31.

16 Vogt MT, Cauley JA, Kuller LH, Nevitt MC. Functional status and mobility among elderly women with lower extremity arterial disease: the Study of Osteoporotic Fractures. J Am Geriatr Soc 1994;42:923-9.

17 Lin MY, Gutierrez PR, Stone KL, Yaffe K, Ensrud K, Fink HA, et al. Vision impairment and combined vision and hearing impairment predict cognitive and functional decline in older women. / Am Geriatr Soc 2004;52:1996-2002.

18 Rodgers W, Miller B. A comparative analysis of ADL questions in surveys of older people. J Gerontol B Psychol Sci Soc Sci 1997;52:21-36.

19 Elston JM, Koch GG, Weissert WG. Regression-adjusted small are estimates of functional dependency in the noninstitutionalized American population age 65 and over. Am J Public Health 1991;81:335-43.

20 Lord SR, McLean D, Stathers G. Physiological factors associated with injurious falls in older people living in the community. Gerontology 1992;38:338-46.

21 Bauer D, Browner WS, Cauley JA, Orwoll ES, Scott JC, Black DM, et al. Factors associated with appendicular bone mass in older women. Ann Intern Med 1993;118:657-65.

22 Lubben JE. Assessing social networks among elderly populations. Fam Community Health 1988;11:42-52.

23 Rutledge T, Matthews K, Lui LY, Stone KL, Cauley JA. Social networks and marital status predict mortality in older women: prospective evidence from the Study of Osteoporotic Fractures (SOF). Psychosom Med 2003;65:688-94.

24 Teng EL, Chui HC. The modified mini-mental state (3MS) examination. J Clin Psychiatry 1987;48:314-8.

25 Fredman L, Droge JA, Rabin DL. Functional limitations among home health care users in the national health interview survey supplement on aging. Gerontologist 1992;32:641-6. 
26 Kosorok MR, Omenn GS, Diehr P, Koepsell TD, Patrick DL. Restricted activity days among older adults. Am J Public Health 1992;82:1263-7.

27 Shah BV, Barnwell BG, Bieler GS. SUDAAN user's manual release 7.5. Research Triangle Institute, 1997.

28 Lord SR, Clark RD, Webster IW. Physiological factors associated with falls in an elderly population. J Am Geriatr Soc 1991;39:1194-200.

29 Lord SR, Menz HB, Tiedemann A. A physiologic profile approach to falls risk assessment and prevention. Phys Ther 2003;83:237-52.

30 Lord SR, Clark RD, Webster IW. Visual acuity and contrast sensitivity in relation to falls in an elderly population. Age Ageing 1991;20:175-81.

31 Steffen TM, Hacker TA, Mollinger L. Age- and gender-related test performance in community-dwelling elderly people: six-minute walk test, Berg balance scale, timed up \& go test, and gait speeds. Phys Ther 2002;82:128-37.

32 Lord SR. Instability and falls in elderly people. In: Lord SR, ed. Facts and research in gerontology: falls, gait and balance disorders in the elderly. Springer Publishing Company, 1996.

33 Berg KO, Wood-Dauphinee SL, Williams JI, Maki B. Measuring balance in the elderly: validation of an instrument. Can J Public Health 1992;83:S7-11.

34 Bailey IL, Lovie JE. New design principles for visual acuity letter charts. Am J Optom Physiol Opt 1976;53:740-5.

35 Lord SR, Menz HB. Visual contributions to postural stability in older adults. Gerontology 2000;46:306-10.

36 Lord SR, Dayhew J. Visual risk factors for falls in older persons. J Am Geriatr Soc 2001;49:508-15.

37 Zeger SL, Liang KY, Albert PS. Models for longitudinal data: a generalized estimating equation approach. Biometrics 1988;44:1049-60.

38 Zeger SL, Liang KY. Longitudinal data analysis for discrete and continuous outcomes. Biometrics 1986;42:121-30.

39 Greene E, Frawley W. Evaluating models of collinearity judgment for reliability and scale. Perception 2001;30:543-58.

40 Beaule PE, Dervin GF, Giachino AA, Rody K, Grabowski J, Fazekas A. Self-reported disability following distal radius fractures: the influence of hand dominance. J Hand Surg Am 2000;25:476-82.

41 Goldfarb CA, Rudzki JR, Catalano LW, Hughes M, Borrelli J Jr. Fifteenyear outcome of displaced intra-articular fractures of the distal radius. J Hand Surg Am 2006;31:633-9.

42 Altissimi M, Antenucci R, Fiacca C, Mancini GB. Long-term results of conservative treatment of fractures of the distal radius. Clin Orthop Rel Res 1986;206:202-10.
43 Brenneman SK, Barrett-Connor E, Sajjan S, Markson LE, Siris ES. Impact of recent fracture on health-related quality of life in postmenopausal women. J Bone Miner Res 2006;21:809-16.

44 Rozental TDM, Branas CC, Bozentka DJ, Beredjiklian PK. Survival among elderly patients after fractures of the distal radius. J Hand Surg 2002;27A:948-52.

45 MacDermid IC, Donner A, Richards RS, Roth JH. Patient versus injur factors as predictors of pain and disability six months after a distal radius fracture. J Clin Epidemiol 2002;55:849-54.

46 MacDermid JC, Roth JH, Richards RS. Pain and disability reported in the year following a distal radius fracture: a cohort study. BMC Musculoskelet Disord 2003;4:24.

47 Browner WS, Pressman AR, Nevitt MC, Cummings SR. Mortality following fractures in older women: the Study of Osteoporotic Fractures. Arch Intern Med 1996;156:1521-5.

48 Cummings SR, Nevitt MC. Non-skeletal determinants of fractures: the potential importance of the mechanics of falls. Osteoporos Int 1994;4:67-70.

49 Nevitt MC, Cummings SR. Type of fall and risk of hip and wrist fractures: the Study of Osteoporotic Fractures. J Am Geriatr SoC 1993;41:1226-34.

50 MacDermid JC, Roth JH, Richards RS. Pain and disability reported in the year following a distal radius fracture: a cohort study. BMC Musculoskelet Disord 2003;4:24.

51 Fink HA, Ensrud KE, Nelson DB, Kerani RP, Schreiner PJ, Zhao Y, et al. Disability after clinical fracture in postmenopausal women with low bone density: the Fracture Intervention Trial (FIT). Osteoporos Int 2003;14:69-76.

52 Centers for Disease Control and Prevention, National Institutes of Health. Healthy people 2010: arthritis, osteoporosis, and chronic back conditions. 2010. www.healthypeople.gov/Data/midcourse/ pdf/fa02.pdf.

53 Cummings SR, Melton LJ. Epidemiology and outcomes of osteoporotic fractures. Lancet 2002;359:1761-7.

54 Burge R, Dawson-Hughes B, Solomon DH, Wong JB, King A, Tosteson A. Incidence and economic burden of osteoporosis-related fractures in the United States, 2005-2025. J Bone Miner Res 2007;22:465-75.

55 National Center for Health Statistics. United States Census Data, 2001.

Accepted: 27 April 2010 